\title{
Patenting an Accessory for a Light Microscope
}

\section{Douglas Clark}

Paedia LLC, 15 Conrad Street, San Francisco CA 94131-2924

dclark@paedia.com

\begin{abstract}
The U.S. Patent and Trademark Office (PTO) encourages independent inventors who are not patent professionals to file and prosecute their own patent applications. Self-help books are useful guides for navigating through the PTO's many laws and rules. When an inventor has an idea, he should document it, have the document witnessed, search all public records for novelty and unobviousness, and finally file an application with the PTO. The inventor defends his idea with an Examiner from the PTO and, if all requirements are met, receives a patent that grants the inventor a monopoly to make, use, and sell his invention for a period of time.
\end{abstract}

Keywords: Inventions, patent applications, U.S. Patent and Trademark Office, electrically variable focus lens, light microscopy

\section{Introduction}

In the July 2015 issue of Microscopy Today [1], I presented an image acquisition system that I had recently patented [2]. My invention uses a lens with electrically variable focal length (VFL) in combination with hardware and software that makes possible the rapid acquisition of images for focus stacking. I wrote and prosecuted the patent application myself. I believe that everyone has at least one patentable idea during their life, and in most cases they can patent the idea themselves. Doing this saves money and increases one's knowledge about how intellectual property law works. There are several books on the market that explain the patenting process. I have used one of these since it was first printed 30 years ago; it is now in its 19th edition. It is called Patent It Yourself (PIY) by patent attorney David Pressman [3]. This book explains what a patent is, that is, the granting under law of a monopoly to make, use, and sell an invention; what kinds of things are patentable, that is, the statutory requirements according to law; and how an invention must be novel and unobvious in order to receive a patent. The book also discusses applying for foreign patents. Prosecuting and enforcing foreign patents is onerous and expensive. I prefer to apply for U.S. patents only.

I am an engineer, not a patent attorney or agent. In what follows, I give no legal advice, only an overview of my experiences during the application process at the U.S. Patent and Trademark Office (PTO). I have successfully prosecuted 28 of my own patent applications.

I think of do-it-yourself books as looking forward through the application process, that is, they tell you how to take a series of steps that can result in a patent. I have published 3 books at Amazon that contain file histories of my own patent applications [4-6]. My books are retrospectives that show how I worked through the process from start to finish. I recommend reading them for an in-depth view of my successes in 3 different circumstances. The books show what succeeded in the face of various obstacles that I encountered during prosecution of an application. In some situations, it is best to consult a patent attorney or agent. I have done this numerous times.

\section{The Patenting Process}

Make a record. I keep records of my ideas in notebooks. When I think an idea is patentable, I have one or more witnesses sign and date my record. That way I can prove I invented it in case someone appropriates my idea. There is more information about this topic on the PTO website (www.uspto.gov), search: "derivation proceeding."

Search. Before filing a patent application, I always make sure my idea is workable and fits into one of the categories of patentable subject matter. Then I do an online search to be sure my idea is both novel and unobvious. I use the PTO's online searching tools as well as popular search engines such as Google. In the past I hired a professional searcher because they are experienced in searching and have access to more extensive databases than are available to the general public, including some that are overseas. However a PTO Examiner can sometimes find references that a searcher misses. Because of this, I do the best search I can and then file an application.

File. On March 16, 2013, the PTO introduced a first-inventor-to-file (FITF) system. See more about this on the PTO's website. It impacts prosecution by giving priority to the first inventor to file an application. The application can be either a Provisional Patent Application (PPA) or a regular Utility Patent Application (UPA). Filing a PPA, discussed below, can secure a filing priority date at a reasonable cost and buy more time for searching and testing the marketplace.

\section{Connecting with the PTO}

PTO website and EFS-Web. The PTO has a large and useful website at www.uspto.gov. Most interaction with the PTO is done through this site. I have an account with the Electronic Filing System Web (EFS-Web) [7] at the PTO. This account is set up through the PTO's website and is free. It simplifies the filing of applications, checking their status, and paying fees. It also returns receipts that indicate what has been filed and payments that have been made.

A number of forms are required when submitting information to the PTO [8]. Forms are filed in Portable Document Format (PDF) and are signed electronically. This is done by adding a slash before and after the name of the signer, that is, /John Doe/. When a form also asks for a printed signature, it is simply typed as John Doe. Letters can be signed with the signature printed and in longhand, then scanned and saved as a PDF.

There are private and public Patent Application Information Retrieval (PAIR) systems $[9,10]$ at the PTO. Only registered eFilers have access to the Private PAIR where they can view records related to their applications. Published patents and applications are available to all via the Public PAIR system. When the PTO receives a patent application, it opens a file history record that will contain all correspondence between the applicant or their agent, such as an attorney, and the PTO. When a patent issues and all fees are paid, the prosecution record is closed. The closed record is called a File Wrapper. 


\section{Unlock Multidimensional Nanoelectrical Information}

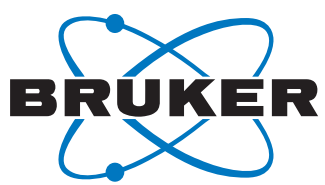

\section{The Most Complete Array of Electrical AFM Techniques}

Bruker's new DataCube modes drastically expand AFM nanoelectrical capabilities by enabling the easy acquisition of multidimensional data cubes. Where conventional AFM electrical modes captured a single image, researchers can now acquire hundreds of images at once, acquire an electrical spectrum at every pixel, and discover previously hidden information in minutes.

\section{Discover More with}

- Electrical spectra at every pixel for more information than with any other electrical mode

- Simultaneous capture of nanoelectrical and nanomechanical data in a single measurement

- Access to previously hidden material information in minutes

- DataCube modes: DCUBE-TUNA, DCUBE SCM, DCUBE-PFM, DCUBE-CR-PFM, DCUBE-SSRM, DCUBE-sMIM

\section{Your research deserves the very best that AFM technology has to offer!}

Visit www.bruker.com/NanoElectricalLab, email productinfo@bruker.com

or call +1.805 .967 .1400 / 800.873.9750 for more information today. 


\section{Filing a Provisional Patent Application (PPA)}

A PPA is not required and by itself it doesn't result in a patent. It costs much less than a regular utility application and is good for one year. Because of FITF, the timing of disclosure of an invention is important and makes filing a PPA worthwhile in many cases. The importance of a PPA can be seen from the following PTO statement: "A provisional application provides the means to establish an early effective filing date in a later filed nonprovisional patent application filed under 35 U.S.C. $\$ 111(\mathrm{a})$. It also allows the term "Patent Pending" to be applied in connection with the description of the invention" [11].

For a PPA, I submit the following paperwork via the EFS: a Provisional Cover Sheet form, Specification, that is, a written description, and Drawings. After the paperwork is submitted, I pay a filing fee with a credit card. The disclosure of an invention in a PPA must be as complete as possible in order to receive a filing date for the material it contains. No claims are required. I put everything I know about the invention into a PPA and describe as many different embodiments, that is, versions, as possible. After that, I have up to one year from filing to evaluate the market potential of the invention before I file a regular utility patent application. Dates and deadlines are absolutely important at all stages of the application process.

\section{Filing and Prosecuting a Utility Patent Application (UPA)}

For a nonprovisional UPA, I submit the following paperwork via the EFS: the Specification, Abstract, Claims, Drawings, Utility Patent Application Transmittal, Application Data Sheet, Nonpublication Request, Information Disclosure Statement, and a Declaration. The purposes of these forms are explained in the book PIY and on the PTO's website. If I previously filed a PPA for the same application, I include a cross reference to its application number in the paperwork. After the paperwork is submitted, I pay application filing fees with a credit card. There are three fee structures available at filing and also some fees that are charged later. They are "Micro Entity," "Small Entity," and "Large Entity." I have always paid Small Entity fees since I've either filed alone or with a business partner. Eligibility for the different fees is explained on the PTO's website.

Then the waiting starts. It usually takes at least a year for the PTO to respond, although for a hefty fee they will move an application to the front of the line. If there are deficiencies in the paperwork that was filed, such as a missing part or a missing signature, the PTO will send a notice to the address of record. Deficiencies must be corrected before prosecution can proceed. If there are no deficiencies, a first Office Action (OA) will appear in the mail at the address of record.

\section{First Office Action}

The first OA contains a checklist of items that are either approved or must be corrected in order for prosecution to proceed. Drawings must be done according to PTO rules, a Specification including a Summary, Abstract, and Claims must be in the proper format. In my experience, the specification, abstract, and drawings have almost always been correct as filed, and some or all of the claims are either objected to or rejected. After the checklist, there are several pages in which the Examiner explains the reasons for these rejections and objections.

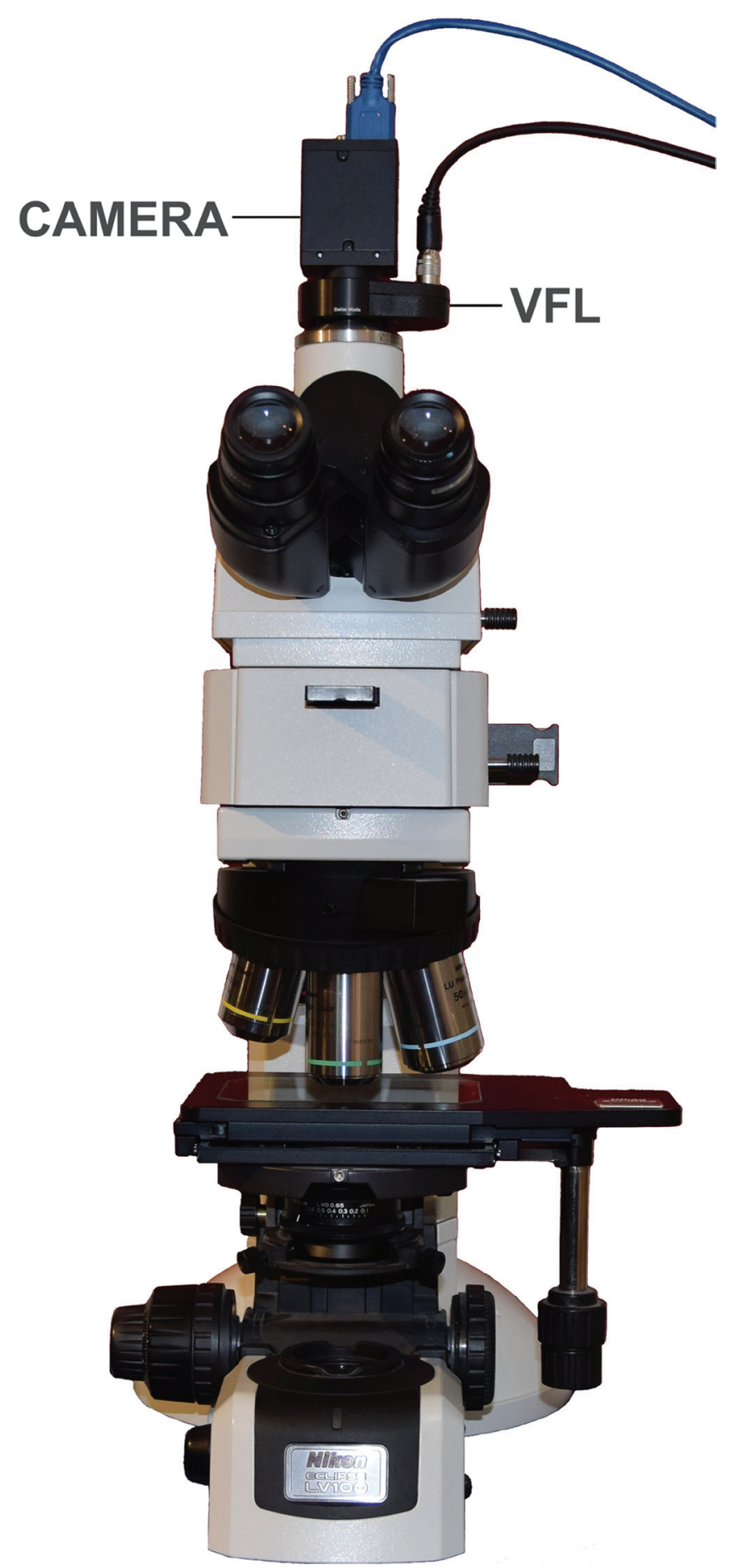

Figure 1: One embodiment, i.e., version, of the patented invention showing a camera and a variable focus lens (VFL) mounted on the trinocular port of a Nikon Eclipse LV100 microscope. The camera is connected to a personal computer, and the VFL is connected to computer-controlled custom driver electronics that are described in the patent of Figure 2.

Each application covers only one invention. If an application includes more than one invention, the Examiner will require restriction of the present application to a single invention. It is possible to file additional applications for other aspects of the same invention that keep the original filing date. That subject is covered in PIY and elsewhere. 
(12) United States Patent Clark et al.
(10) Patent No.:

(45) Date of Patent:
US 8,212,915 B1

Jul. 3, 2012
(54) EXTERNALLY ACTUABLE PHOTO-EYEPIECE RELAY LENS SYSTEM FOR FOCUS AND PHOTOMONTAGE IN A WIDE-FIELD IMAGING SYSTEM

(76) Inventors: Lloyd Douglas Clark, San Francisco, CA (US); Brian A. Brown, San Francisco, CA (US); William T. Davids, Palo Alto, CA (US)

(*) Notice: Subject to any disclaimer, the term of this patent is extended or adjusted under 35 U.S.C. 154 (b) by 114 days.

(21) Appl. No.: 12/853,406

(22) Filed: Aug. 10, 2010

\section{Related U.S. Application Data}

(63) Continuation-in-part of application No. 12/748,412, filed on Mar. 27, 2010.

(60) Provisional application No. 61/356,012, filed on Jun. 17, 2010.

(51)

$\begin{array}{lr}\text { Int. Cl. } & \\ \text { G03B } 13 / 00 & (2006.01) \\ \text { G02B 13/16 } & (2006.01) \\ \text { G02B } 1 / 06 & (2006.01) \\ \text { U. } & \text { Cl }\end{array}$

(52) U.S. Cl. 348/345; 348/335; 359/665; 359/666

(58) Field of Classification Search $359 / 665$, $359 / 666 ; 348 / 335,345$ See application file for complete search history.

\section{References Cited}

\section{U.S. PATENT DOCUMENTS}

$\begin{array}{llll}4,466,703 & \text { A } & 8 / 1984 & \text { Nishimoto } \\ 4,572,616 & \text { A } & 2 / 1986 & \text { Kowel et al. } \\ 5,212,583 & \text { A } & 5 / 1993 & \text { Vali et al. } \\ 6,747,806 & \text { B2 } & 6 / 2004 & \text { Gelbart }\end{array}$

\begin{tabular}{|c|c|c|c|}
\hline $6,778,246$ & B2 & $8 / 2004$ & Sun et al. \\
\hline $7,002,737$ & $\mathrm{~B} 1 *$ & $2 / 2006$ & Akiyama et al. ............. 359/368 \\
\hline $7,191,372$ & $\mathrm{~B} 1 *$ & $3 / 2007$ & Jacobson et al. ............ $7144 / 724$ \\
\hline $7,256,943$ & $\mathrm{~B} 1$ & $8 / 2007$ & Kobrin et al. \\
\hline $7,564,386$ & $\mathrm{~B} 2 *$ & $7 / 2009$ & Barford ............. \\
\hline $7,672,059$ & B2 & $3 / 2010$ & Batchko et al. \\
\hline $7,675,686$ & $\mathrm{~B} 2$ & $3 / 2010$ & Lo et al. \\
\hline $2005 / 0270639$ & $\mathrm{Al} *$ & $12 / 2005$ & $359 / 381$ \\
\hline $2006 / 0039603$ & $\mathrm{Al} *$ & $2 / 2006$ & Koutsky .......... \\
\hline $2009 / 0052049$ & $\mathrm{Al} *$ & $2 / 2009$ & Batchko et al. .............. 359/666 \\
\hline
\end{tabular}

H. Oku et al., High-speed liquid lens with $2 \mathrm{~ms}$ response and $80.3 \mathrm{~nm}$ root-mean-square wavefront error, Journal, 2009, 221108-1 to 221108-3, vol. 94, Applied Physics Letters, US.

Physikinstrumente GMBH \& Co., www.physikinstrumente.com/en/ products/primages.php?sortnr=200375\&picview=2\#gallery.

* cited by examiner

Primary Examiner - Sinh Tran Assistant Examiner - Mark Monk

\section{ABSTRACT}

A relay lens assembly (100) for use with a microscope (1400), telescope or binocular (1500), comprises a lens element (300) that is responsive to commands, conveyed from a control unit (400), via a conduit (410) between the control unit and the lens element. A computing device $(\mathbf{8 1 0})$ controls operation of the lens assembly and a digital camera $(\mathbf{8 0 5})$ that has an image sensor (125). The control unit causes the lens assembly to assume any of a plurality of predetermined focal lengths so that different depths of an object being imaged can be rendered in-focus on the sensor. A series of images can be taken at predetermined, computer-controlled focal depths. These images can be processed in order to create a photomontage that is in focus at a plurality of predetermined depths in a process commonly called focus-stacking. The addition of a plurality of data input and analysis units $(\mathbf{1 1 0 5})$ and a combiner (1115) makes rapid processing of individual images possible for photomontage at video rates.

\section{Claims, 8 Drawing Sheets}

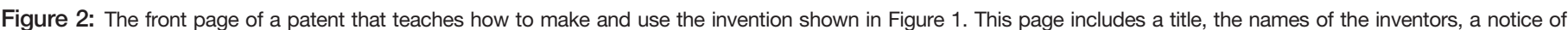

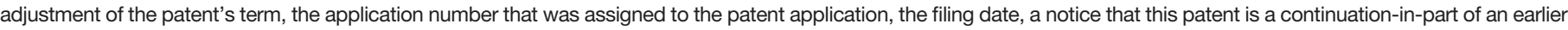

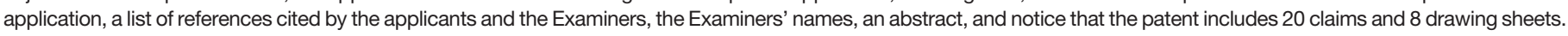

Responding to the first OA. Each and every objection or rejection must be answered. I read the Examiner's letter very carefully and then answer it paragraph by paragraph in a formal letter. Corrections can be made to the original application, but no new information can be entered.
There are usually more OAs. In most cases, I just answer these with another OA response. Examiners are available by phone. I sometimes call one for a short discussion to clarify a point. If it's going to be a deeper conversation, I request a formal telephonic interview. After the interview, both sides 


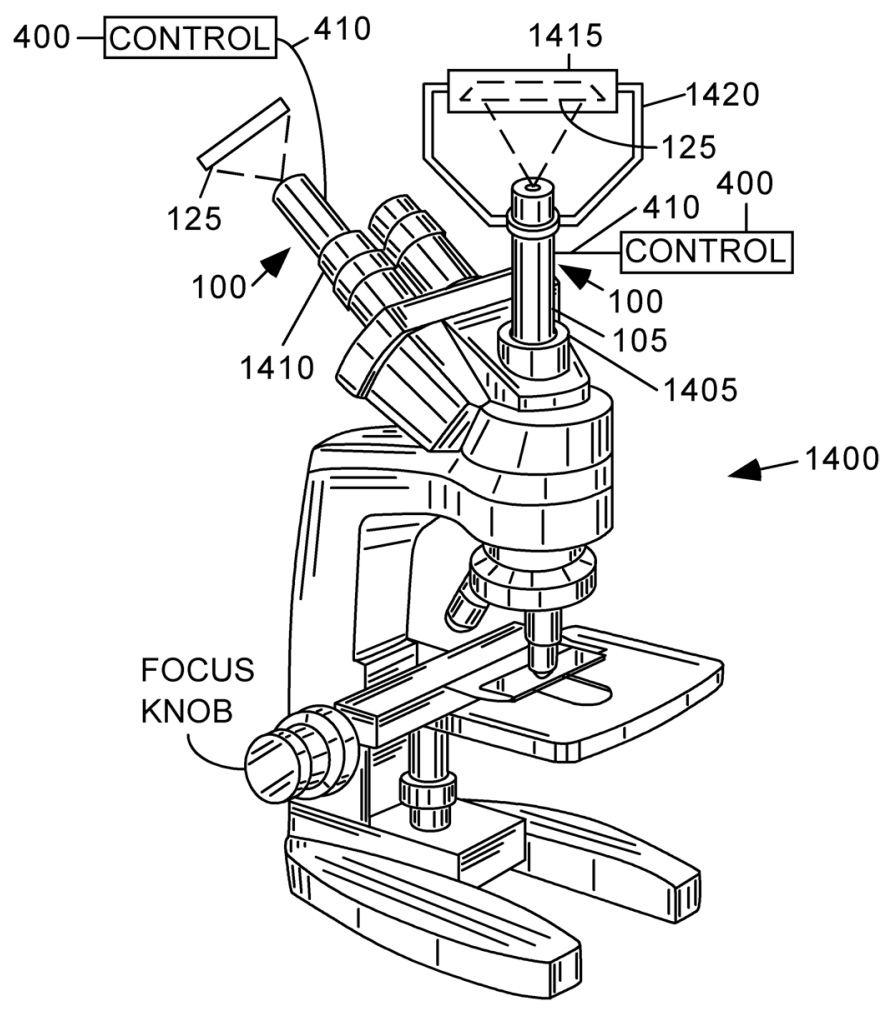

Figure 3: A figure from the patent of Figure 2. The numbers identify each part that is discussed in the text. This figure shows two embodiments that are mounted on a microscope 1400. In a first embodiment a VFL 100 receives an image from a microscope's eyepiece 1410 and focuses the image onto a photosensor array 125. In a second embodiment, a VFL 100 is mounted on a microscope's trinocular port 1405 and focuses an image onto a photosensor array 125 in a housing 1415.

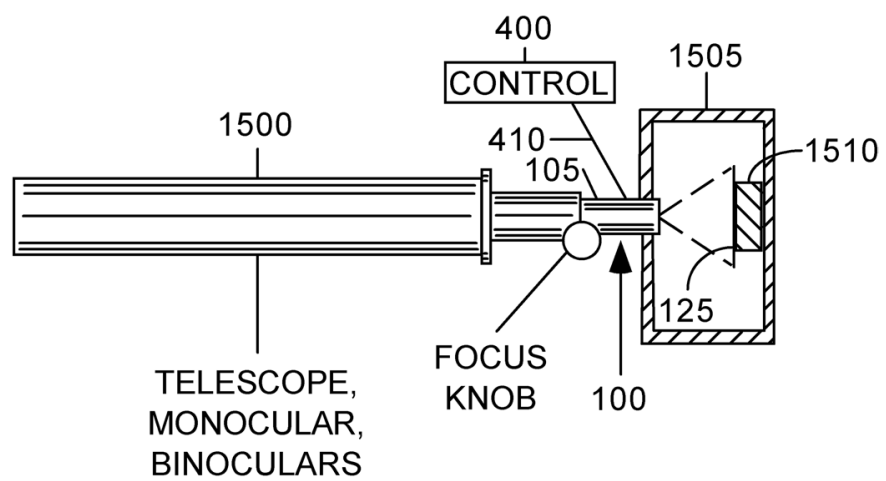

Figure 4: A figure from the patent of Figure 2. Other embodiments of the invention include the same concept applied to telescopes, monoculars, and binoculars. The VFL 100 is mounted between the objective optics 1500 and a photosensor array 125.

file a form or letter stating the substance of the interview and whether agreement was reached. An interview can be very helpful. Having both sides on the same page can shorten the time for prosecution.

At some point in the examination, an Examiner will decide that an OA is "Final." This just means that the rules for responding are different, and it will probably be necessary to pay another fee for continued examination. Eventually someone will blink. My book about File Wrapper \#2 [5] tells about a drawn out prosecution that ended in my favor only after I prepared to file an appeal that would cause other Examiners to weigh in on prosecution of the application.

\section{Issuance}

When an application has survived all the examination hurdles, I receive a Notice of Allowance, a Notice of Allowability, and an explanation of allowability from the Examiner. At this point, I pay the Issue Fee. The PTO then issues my patent, and it will have a life of 20 years from the filing date, plus any adjustments made by the PTO.

\section{Conclusion}

The patenting process is governed by many laws and rules. I have found that the most important and commonly encountered ones are taught in self-help references and on the PTO's website. I do consult a patent attorney when I'm unsure of how to proceed, but after having filed and successfully prosecuted a number of applications I am confident that I can patent it myself.

\section{References}

[1] LD Clark et al., Microscopy Today 23(4) (2015) 18-24.

[2] LD Clark et al., Externally Actuable Photo-Eyepiece Relay Lens System for Focus and Photomontage in a Wide-Field Imaging System. U.S. Patent 8,212,915, July 03, 2012, https://paedia.com/Patents/US8212915.pdf.

[3] David Pressman, Esq., Patent It Yourself, Nolo, Berkeley, CA, 2018.

[4] LD Clark, Patent Chronicles: Patenting It Myself: File Wrapper \#1: Examination Accelerated With a Petition to Make Special, Paedia LLC, San Francisco, 2018, ISBN 9781718151901.

[5] LD Clark, Patent Chronicles: Patenting It Myself: File Wrapper \#2: Examination With A Successful Pre-Appeal Brief Review, Paedia LLC, San Francisco, 2018, ISBN 9781718132498.

[6] LD Clark, Patent Chronicles: Patenting It Myself: File Wrapper \#3: Shortening An Examination With An Interview, Paedia LLC, San Francisco, 2018, ISBN 9781718132672.

[7] United States Patent and Trademark Office, "About EFS-Web.” https://www.uspto.gov/patents-applicationprocess/applying-online/about-efs-web (accessed August 31, 2018).

[8] United States Patent and Trademark Office, "Forms For Patent Applications Filed On Or After September 16, 2012." https://www.uspto.gov/patent/forms/forms-patentapplications-filed-or-after-september-16-2012 (accessed August 31, 2018).

[9] United States Patent and Trademark Office, "Check the filing status of your patent application." https://www.uspto. gov/patents-application-process/checking-applicationstatus/check-filing-status-your-patent-application (accessed August 31, 2018).

[10] United States Patent and Trademark Office, "Public Patent Application Information Retrieval.” https://portal. uspto.gov/pair/PublicPair (accessed August 31, 2018).

[11] United States Patent and Trademark Office, "The Provisional Patent Application: Is it for Me?” https:// www.uspto.gov/learning-and-resources/newsletter/ inventors-eye/provisional-patent-application-it-me (accessed August 31, 2018). 


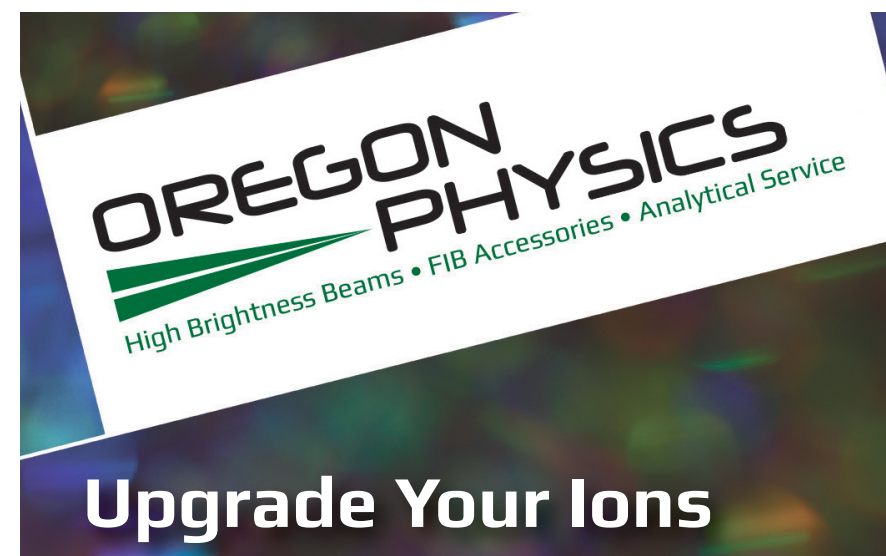

Hyperion ${ }^{\mathrm{TM}}$ Dual Polarity Ion Sources are now available as direct upgrades from Oregon Physics for FEI FIB 200, PHI Adept 1010, and Cameca NanoSIMS, IMS F series, and 12XX series instruments.

Upgrade your ion source to benefit from:

- Longer source lifetime

- Better image resolution

- Improved depth profiling (SIMS)

- Higher currents for milling (FIB)

Oregon Physics' Hyperion ion sources are designed to bolt-on to your existing optical system for easy implementation.

How will Hyperion improve your research? Learn more at Oregon-Physics.com or call us to discuss your requirements.

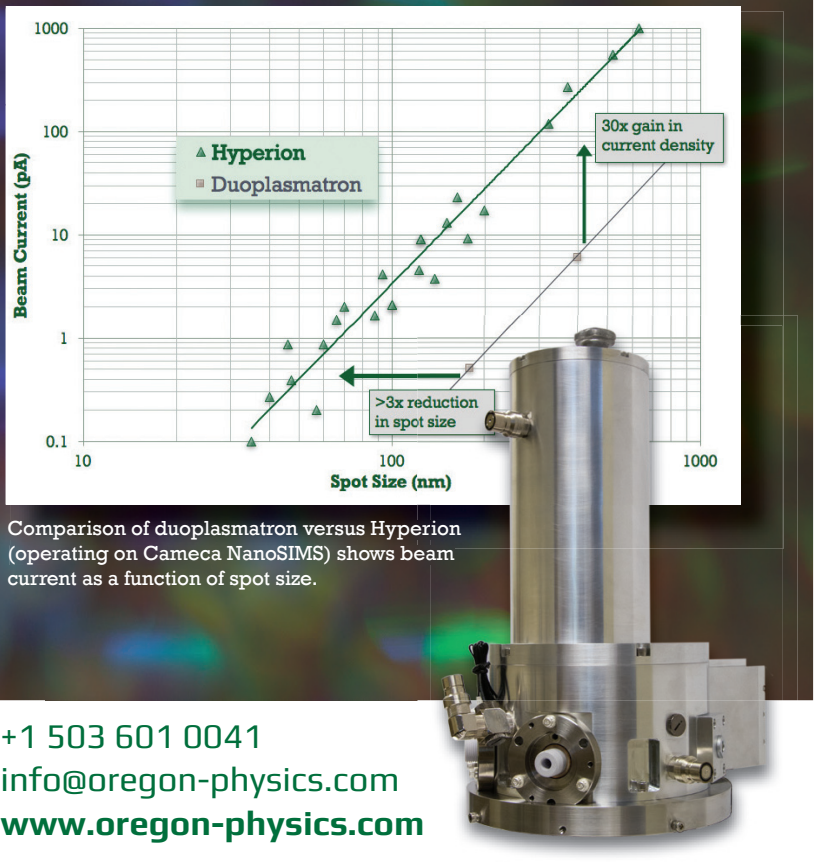

\section{8 lumencor}

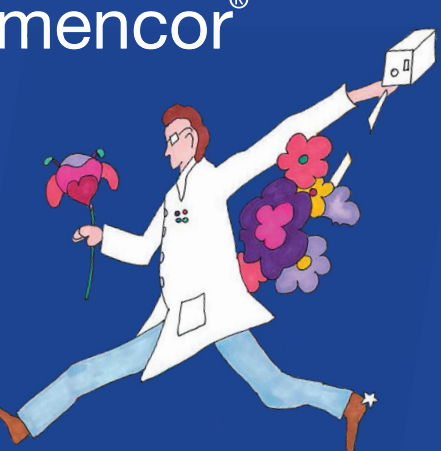

SOLA SE nIR LIGHT ENGINE

THE BRIGHTEST solid-state lamp in the life sciences Now includes $\mathrm{NIR}$ in addition to UV and VIS

SOLA SE nIR Light Engine Spectrum
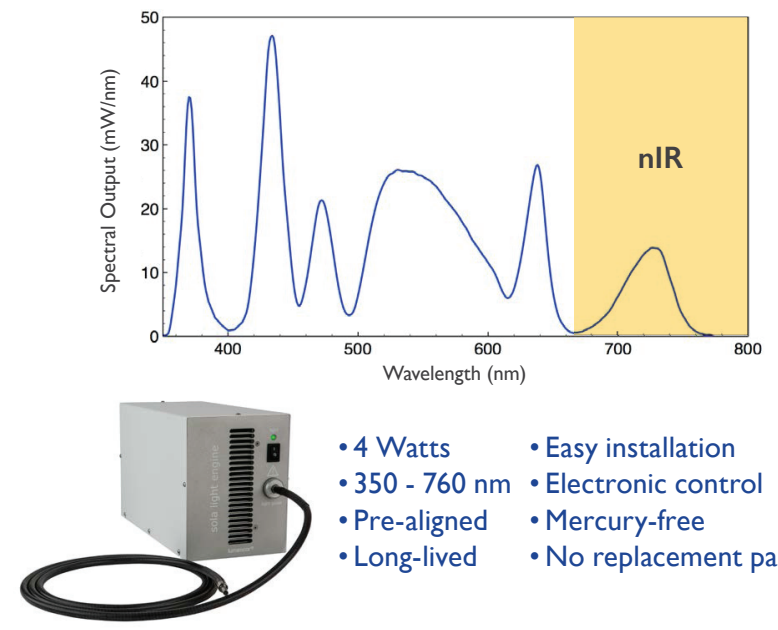

- 4 Watts Easy installation

- 350 - 760 nm • Electronic control

- Pre-aligned - Mercury-free

- Long-lived - No replacement parts

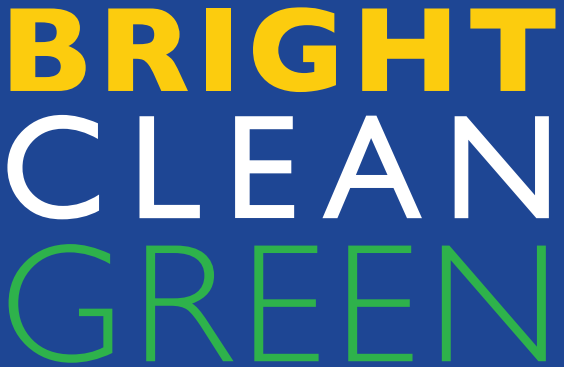

SOLID-STATE ILLUMINATION 